\title{
Pelo direito de brincar: conhecendo a infância e potencializando a ação da terapia ocupacional ${ }^{*}$
}

\author{
The right to play: getting to know childhood and \\ enhancing occupational therapy's action
}

\author{
Marta Aoki ${ }^{1}$, Fátima Corrêa Oliver ${ }^{2}$, Stella Maris Nicolau ${ }^{3}$
}

AOKI, M.; OLIVER, F. C.; NICOLAU, S. M. Pelo direito de brincar: conhecendo e potencializando a ação da Terapia ocupacional. Rev. Ter. Ocup. Univ. São Paulo, v. 17, n. 2, p. 57-63, maio/ago., 2006.

\begin{abstract}
RESUMO: Trata-se de relato sobre desenvolvimento de grupo de atividades lúdicas com crianças (entre 5 e 14 anos) realizado no espaço de uma rua, em bairro periférico do município de São Paulo. O grupo foi coordenado por equipe (um terapeuta ocupacional e dois estudantes de terapia ocupacional) vinculada a projeto docente assistencial da universidade e unidade básica de saúde entre abril de 2004 e julho de 2005 . A partir de registros de atividades assistenciais e discussões coletivas entre equipe e profissionais do projeto recuperou-se a trajetória da experiência. A equipe se deslocava para a rua e durante duas horas realizava atividades lúdicas, jogos e conversas. A compreensão da dinâmica das crianças na rua e a promoção de convivência pautada em experiências de aprendizagem e solidariedade foram eixos norteadores dos encontros grupais. No contato com as crianças na rua observaram-se embates na utilização do espaço público e demandas individuais. Foram percebidas relações interpessoais conflituosas entre crianças, que exigiam mediação dos adultos e a necessidade de contato com pais. Foram entrevistadas 10 famílias (com total de 17 crianças participantes) para conhecer a constituição familiar, o rendimento das crianças na escola, as atividades que realizavam no tempo livre, as brincadeiras preferidas e atividades de lazer da família. Houve significativa adesão e reconhecimento positivo da experiência por parte das crianças e a equipe pode compreender a complexidade das condições vividas pelas crianças da área de abrangência de uma unidade de saúde, fomentando discussão sobre a criação de outras alternativas assistenciais no serviço e sobre direitos.
\end{abstract}

DESCRITORES: Criança. Pré-escolar. Desenvolvimento infantil. Defesa da criança e do adolescente. Direitos humanos. Terapia ocupacional.

\footnotetext{
* Trabalho apresentado no IX Congresso Brasileiro de Terapia Ocupacional, Pernambuco, 27 a 30 de setembro de 2005.

${ }^{1}$ Terapeuta Ocupacional do Departamento Fisioterapia, Fonoaudiologia e Terapia Ocupacional da FMUSP. Mestranda em Ciências da Reabilitação - FMUSP.

${ }^{2}$ Docente do Departamento Fisioterapia, Fonoaudiologia e Terapia Ocupacional da FMUSP.Doutora em Saúde Pública.

${ }^{3}$ Terapeuta Ocupacional da Unidade Básica de Saúde do Jardim Boa Vista - Secretaria Municipal de Saúde de São Paulo. Mestre em Psicologia Social.

Endereço para correspondência: Departamento de Fisioterapia, Fonoaudiologia e Terapia Ocupacional da FMUSP. Rua Cipotânea, 51. Cidade Universitária - CEP 05360-160 - São Paulo SP. email: aoki@usp.br
} 


\section{INTRODUÇÃO}

$\mathrm{D}$ esde 2001, o Laboratório de Reabilitação com Ênfase no Território do Curso de Terapia Ocupacional da Faculdade de Medicina da USP desenvolve projeto docente assistencial com a Unidade Básica de Saúde - UBS do Jardim Boa Vista da Secretaria Municipal de Saúde de São Paulo. Nesse projeto, procura-se articular ensino de graduação em terapia ocupacional com as necessidades e demandas das pessoas acompanhadas pela UBS, adultos, crianças, adolescentes e idosos, portadores ou não de deficiências. Participam do projeto uma terapeuta ocupacional e uma docente da Universidade, uma terapeuta ocupacional da UBS, estudantes de terapia ocupacional de $2^{\circ}$ e $3^{\circ}$ anos, em prática supervisionada e estudantes de $4^{\circ}$ ano, em estágio supervisionado. Neste relato será apresentado um aspecto do trabalho assistencial do projeto: a constituição e desenvolvimento de grupo de atividades lúdicas realizado no espaço da rua, coordenado por equipe composta por um terapeuta ocupacional da USP e dois estudantes de terapia ocupacional de $4^{\circ}$ ano. $\mathrm{O}$ relato foi organizado a partir do estudo de registros de atividades assistenciais e de discussões coletivas entre profissionais e estudantes, realizados no período de desenvolvimento do grupo.

O grupo, que se intitulava Brincando na Rua, mantinha encontros semanais com duas horas de duração, com a participação de cerca de 15 crianças, por encontro, e foi desenvolvido no período de abril de 2004 a julho de 2005, tendo realizado 42 encontros. Participaram do grupo 38 crianças (18 meninas e 20 meninos), sendo 17 delas mais assíduas.

\section{Brincando na Rua: histórico e desenvolvimento do grupo}

No ano de 2004, aconteceram dois encontros entre representantes das escolas de educação infantil e ensino fundamental da área de abrangência da UBS Jardim Boa Vista, terapeutas ocupacionais da USP e da UBS, psicóloga e fonoaudióloga da UBS para intercâmbio de experiências e discussões conjuntas sobre a situação da infância da região. Num dos encontros, para encaminhamentos de situações comuns vivenciadas pelos professores e referidas ao fracasso escolar e indisciplina dos alunos, a coordenação pedagógica da escola de ensino fundamental levantou a situação vivenciada por W., um menino de 12 anos de idade.

W. tinha problemas familiares importantes, que resultavam em dificuldades para manter sua assiduidade à escola. Freqüentemente agredia, física e verbalmente, professores e colegas, o que, por vezes, impossibilitava sua permanência no ambiente escolar. A mãe de W. falecera há alguns meses, vítima de complicações clínicas decorrentes de imunodeficiência adquirida. W. participava de atendimento psicológico grupal na UBS, era pouco assíduo e quando se apresentava agredia fisicamente os colegas do grupo, o que desorganizava o acompanhamento realizado. Diante dessa situação, os terapeutas ocupacionais da USP e da UBS se dispuseram a aprofundar o conhecimento da condição vivenciada por W. e ampliar a abordagem de sua problemática, levando em conta a complexidade da situação familiar, a necessidade de estabelecimento de vínculo com W. seu pai e seus irmãos, propondo-se inicialmente a realização de um contato direto com a família através de visita domiciliar. Vale ressaltar, que a UBS desenvolve o Programa de Saúde da Família, onde a visita domiciliar é desenvolvida regularmente por agentes comunitários de saúde, médicos, enfermeiras, auxiliares de enfermagem e terapeuta ocupacional.

Durante as duas primeiras visitas pode-se conhecer o contexto familiar: as dificuldades vivenciadas pelo pai para prover os cuidados cotidianos dos filhos de 12 (doze), 8 (nove) e 5 (cinco) anos de idade, como também para a geração de renda, pois trabalhava com recolhimento e venda de sucatas, armazenando-as no quintal de seu domicílio. A família morava próximo à rua conhecida como "Rua de Lazer"(1) que contava com a presença de inúmeras crianças brincando, entre elas W. e seus irmãos. Nessas visitas pode-se observar as crianças atuando livremente, as brincadeiras que realizavam, a participação espontânea de W. e de seus irmãos levando a equipe a reafirmar a necessidade de se conhecer a realidade vivenciada por W. e pelas crianças da região, no contexto de moradia e não apenas no serviço de saúde ou na escola. Conhecer as crianças em situações lúdicas poderia facilitar o estabelecimento de vínculo entre serviço de saúde e a família de W. e de outras crianças em situação semelhante. A compreensão, por parte da equipe, das situações vivenciadas por crianças numa região periférica poderia favorecer a articulação entre atividades assistenciais desenvolvidas com crianças na UBS e seu contexto de vida.

Assim, terapeutas ocupacionais, ancorados na afirmação do direito de brincar e buscando aproximar-se do contexto

\footnotetext{
(1) Trata-se da rua Gabriel de Carvalho, assim denominada porque nos anos 1980 era parte de projeto da prefeitura municipal intitulado Rua de Lazer, em que, aos domingos a rua era fechada para tráfego de veículos permitindo a realização de atividades recreativas por iniciativa dos moradores. Ainda hoje tanto adultos como crianças se referem a essa rua como Rua de Lazer.
} 
das crianças, passaram a realizar um grupo de atividades lúdicas na rua como estratégia para conhecer e lidar com a complexidade da situação de W. seus irmãos e de outras crianças que se incorporassem à proposta.

Nas primeiras visitas a equipe observou o brincar e as atividades lúdicas desenvolvidas por W. e outras crianças, exclusivamente meninos, que informavam passar longos períodos do dia em grupo, brincando naquele local. Suas brincadeiras preferidas estavam relacionadas com os recursos que a rua pode oferecer como jogar bola, principalmente futebol, andar de bicicleta, empinar pipa, jogar bolinha de gude, brincar de pega-pega. No deslocamento pelas ruas até o local do grupo se observava a presença de muitos adultos desocupados, principalmente homens, o intenso fluxo de veículos e a pouca preocupação dos motoristas com a presença das crianças, o que criava situações de risco.

Nos encontros posteriores, a equipe passou a propor atividades lúdicas, resgatando brincadeiras tradicionais infantis (queimada, mãe da rua, duro ou mole entre outras) oferecendo oportunidades para que as crianças confeccionassem seu material lúdico (pipas, brinquedos com sucata entre outros). Também foram realizadas festas e eventos (piquenique na rua, festas junina e de natal e comemorações de aniversários na sede da UBS). Procurouse criar novas possibilidades tanto a partir do repertório das crianças como introduzindo novas brincadeiras e materiais. Nas propostas de atividades houve a preocupação de que as experiências pudessem ser vividas de modo a produzir momentos de convivência e aprendizagem, sempre mantendo a característica fundamental do jogo que é a intenção da criança brincar.

Dezessete crianças participaram mais assiduamente do grupo; 12 meninos e 5 meninas. Desde os primeiros encontros, as crianças se mostraram receptivas ao contato com a equipe. Observou-se dificuldade para estabelecimento de diálogo entre as crianças, para compreender e cumprir acordos e para partilhar brinquedos e materiais. Em muitos momentos, ocorreram situações de intensos conflitos e agressões físicas entre as crianças. Nesse cenário a equipe propunha encontros permeados pela construção do diálogo entre as crianças e entre estas e a equipe, favorecendo uma cultura de resolução não-violenta de conflitos no desenvolvimento das atividades do grupo. Assim, sem imposição das perspectivas dos adultos, foi possível a construção de um vínculo afetivo pautado no respeito e na percepção das potencialidades das crianças.

Progressivamente, as crianças foram percebendo que implementar diálogos e estabelecer acordos era parte da postura da equipe, que afirmava o direito de todos participarem, serem respeitados e ouvidos, cultivando atitudes de negociação e interlocução entre adultos e crianças, favorecendo um ambiente grupal de cooperação, o que não significava falta de autoridade dos adultos. Assim, foram se estabelecendo relações interpessoais menos hierárquicas que aquelas que as crianças vivenciavam com outros adultos nos espaços institucionais da escola, da vizinhança ou da família. Por outro lado, no desenvolvimento dos encontros algumas crianças se mostravam resistentes em realizar jogos e brincadeiras que exigissem habilidades intelectuais (escrita ou cálculos matemáticos), outras ainda se mostravam ansiosas, reafirmando, a todo o momento, sua inabilidade/incapacidade para realizar desenhos, pinturas ou construir brinquedos, trazendo para o grupo situações, provavelmente experimentadas no processo de escolarização ou na família. As intervenções dos adultos buscavam afirmar as possibilidades de cada um facilitando a superação de obstáculos para o desenvolvimento dos jogos e brincadeiras, através de adaptações de materiais ou de regras e sempre mediando situações de conflito. Observar e compreender estas situações, relacionadas à dinâmica social e cultural da vida das crianças, foi fundamental para possibilitar a participação de todos durante os encontros e a exploração e ampliação das habilidades e capacidades de cada criança.

O espaço da brincadeira na rua era mais ocupado pelos meninos, no entanto, com a estruturação de atividades, proporcionada pelos encontros do grupo, as meninas passaram a serem autorizadas pelos familiares a participarem das atividades, pois algumas delas estavam impossibilitadas pelas responsabilidades de realização das tarefas domésticas e do cuidado dos irmãos mais novos. O maior contato com as crianças da região e a necessidade de conhecer mais diretamente o contexto familiar das crianças mais assíduas levou à realização de visitas domiciliares a outras crianças e suas famílias, além de W. e seus irmãos.

\section{Brincando na Rua: sobre crianças e suas famílias}

Entre setembro de 2004 e maio de 2005 foram realizadas visitas domiciliares a 10 famílias totalizando 17 entrevistas com familiares de 12 meninos e 5 meninas, participantes do grupo. As entrevistas foram desenvolvidas, geralmente com as mães, a partir de roteiro com questões abertas, que buscou caracterizar a constituição familiar, a freqüência e o rendimento na escola, a participação das crianças em atividades extracurriculares (tanto na escola como fora dela), a ocupação do tempo livre, as brincadeiras preferidas, o círculo de amizades das crianças e os locais de lazer freqüentados pela família. As informações estão apresentadas no Quadro 1. 
AOKI, M. et al. Pelo direito de brincar. Rev. Ter. Ocup. Univ. São Paulo, v. 17, n. 2, p. 57-63, maio/ago., 2006.

Quadro 1 - Aspectos da situação de crianças participantes do grupo Brincando na Rua, segundo responsáveis no período entre 2004 e 2005.

\begin{tabular}{|c|c|c|c|}
\hline Questões & Informações apresentadas & No. & No. Crianças \\
\hline Constituição familiar & $\begin{array}{l}\text { Famílias nucleares (pai mãe e filhos) } \\
\text { Famílias monoparentais (mães e filhos) } \\
\text { Outra formação familiar (tios, sobrinho } \\
\text { e primos) }\end{array}$ & $\begin{array}{l}6 \\
3 \\
1\end{array}$ & $\begin{array}{l}9 \\
7 \\
1\end{array}$ \\
\hline Freqüência escolar & $\begin{array}{l}\text { Matriculadas na escola } \\
\text { Sem matrícula na escola }\end{array}$ & $\begin{array}{l}16 \\
1\end{array}$ & 17 \\
\hline Rendimento escolar & $\begin{array}{l}\text { Baixo aproveitamento escolar } \\
\text { Sem problemas de aproveitamento escolar } \\
\text { Familiar não respondeu à questão }\end{array}$ & $\begin{array}{l}6 \\
9\end{array}$ & $\begin{array}{l}15 * * \\
1 \\
\end{array}$ \\
\hline Ocupação do tempo livre* & $\begin{array}{l}\text { Em brincadeiras } \\
\text { Assistindo TV } \\
\text { Jogando vídeo-game } \\
\text { Familiar não respondeu à questão }\end{array}$ & $\begin{array}{l}14 \\
5 \\
8\end{array}$ & $\begin{array}{l}16 \\
1 \\
\end{array}$ \\
\hline $\begin{array}{l}\text { Vinculação a atividades } \\
\text { extra-curriculares* }\end{array}$ & $\begin{array}{l}\text { Atividades na Associação local } \\
\text { Esporte (na escola) } \\
\text { Aula de pintura e natação } \\
\text { Fonoaudiologia na UBS } \\
\text { Aulas de reforço escolar (na escola) } \\
\text { Não realizam atividades } \\
\text { Familiar não respondeu à questão }\end{array}$ & $\begin{array}{l}4 \\
1 \\
2 \\
1 \\
1\end{array}$ & $\begin{array}{l}8 \\
6 \\
3 \\
\end{array}$ \\
\hline Brincadeiras preferidas* & $\begin{array}{l}\text { Jogar futebol } \\
\text { Jogar vídeo-game } \\
\text { Empinar pipa } \\
\text { Andar de bicicleta } \\
\text { Bolinha de gude, mãe da rua entre outras } \\
\text { Familiar não respondeu à questão }\end{array}$ & $\begin{array}{l}9 \\
8 \\
4 \\
3 \\
10\end{array}$ & $\begin{array}{l}13 \\
4 \\
\end{array}$ \\
\hline $\begin{array}{l}\text { Locais de lazer freqüentados } \\
\text { pela família* }\end{array}$ & $\begin{array}{l}\text { Rua de Lazer } \\
\text { Igreja } \\
\text { Centro Educacional Unificado - CEU } \\
\text { Shopping Center } \\
\text { Casa de parentes } \\
\end{array}$ & $\begin{array}{l}14 \\
5 \\
5 \\
4 \\
4 \\
\end{array}$ & 17 \\
\hline Círculo de amizades da crianças* & $\begin{array}{l}\text { Amigos da Rua } \\
\text { Amigos da escola } \\
\text { Familiar não respondeu à questão }\end{array}$ & $\begin{array}{l}15 \\
5 \\
155\end{array}$ & $\begin{array}{l}15 \\
2\end{array}$ \\
\hline
\end{tabular}

* questões que comportavam respostas múltiplas por entrevistado.

** uma criança não freqüentava escola, porque mudou-se para São Paulo, por apenas um semestre, para acompanhar familiar em tratamento.

A constituição das famílias participantes apontou a tendência contemporânea de mudança na instituição familiar sendo que seis famílias eram nucleares e responsáveis por nove crianças do grupo, três famílias eram monoparentais, sob responsabilidade principalmente de mulheres, com sete crianças, mais que o dobro de crianças das famílias nucleares. Além disso, uma criança não convivia com os pais sendo cuidada por tios

As famílias informaram que nove crianças não tinham problemas no rendimento escolar e que seis crianças tinham baixo rendimento, reconhecendo dificuldades de aprendizagem. Os relatos de familiares, o contato com a coordenação pedagógica da escola de ensino fundamental local e a observação da dinâmica das crianças diante das atividades denunciaram uma situação importante de fragilidade na apreensão de conteúdos escolares. Para algumas crianças e familiares a escola tem sido fonte de constantes decepções, um espaço sem atrativos para a aprendizagem e desvinculado de relações de afeto e respeito.

As crianças ocupavam o tempo livre brincando, mas também assistindo TV e jogando vídeo-game.

As brincadeiras preferidas como jogar futebol, empinar pipa e andar de bicicleta eram realizadas principalmente nas ruas. Para alguns pais existia a tentativa de restringir a convivência do filho ao ambiente doméstico, considerandoo mais protegido e saudável para seu desenvolvimento global, mesmo que as casas fossem pequenas, sem quintais e que o cotidiano se restringisse a ir à escola, assistir 
televisão e/ou lidar com jogos eletrônicos.

Apenas sete crianças realizavam atividades extracurriculares, sendo que destas quatro as realizavam na Associação Cultural local, que desenvolve esporte, dança, teatro e curso de informática sendo um pólo de alternativas para crianças e jovens da região.

Os pais também informaram que as crianças, em sua grande maioria, circulavam sozinhas pelo bairro, respondiam pelos seus compromissos escolares, existindo a cultura de responsabilizá-las, precocemente, por atividades que não têm condições de executar com autonomia, mas que mesmo assim as realizam (cumprimento dos horários da escola, cuidar dos irmãos menores, preparar o alimento, limpar a casa, trabalhar entre outras).

O espaço da rua foi reconhecido pelos pais como um dos poucos locais do bairro, onde é possível brincar e cultivar amigos. Porém, também foi compreendido como lugar de exposição a riscos e pouco protegido, favorecendo vivência de situações de violência com constantes agressões físicas ou verbais entre crianças e jovens, onde há convivência com crianças, que contam com pouca proteção dos adultos e familiares e que, por isso, permanecem longos períodos circulando pelo bairro, realizando brincadeiras perigosas, expostas ao trânsito e outros riscos.

Nas entrevistas também ficou claro que crianças e familiares tinham circulação restrita no bairro. Apenas cinco famílias referiram freqüentar o Centro Educacional Unificado - CEU (onde existe a oferta de atividades de esporte, lazer e cultura), pois para isso há necessidade de deslocamento com utilização de transporte. Passeios a locais como cinema, parque, praia entre outros foram pouco citados pelos entrevistados, talvez pela dificuldade de locomoção, falta de recursos financeiros, sensibilização e desconhecimento das oportunidades existentes. A participação das crianças e familiares em instituições religiosas foi lembrada por alguns como um dos locais de lazer que freqüentam, compondo a rede de suporte social das famílias, oferecendo, além do apoio espiritual, auxílio material e afetivo.

As informações das entrevistas puderam ser associadas a outras levantadas pela equipe durante o desenvolvimento dos encontros. Observou-se situações de violência doméstica (com maus tratos e negligência de cuidados), trabalho infantil, dificuldade dos pais em se responsabilizarem pela frequiência dos filhos à escola ou, ainda, problemas emergenciais de saúde. Essas questões obrigaram a equipe a buscar apoio nos recursos comunitários tais como a escola, vizinhos, agentes comunitários e outros profissionais de saúde responsáveis pelo seguimento de determinadas famílias. Também foi necessário acionar o Conselho Tutelar da região e a Associação Comunitária local, para favorecerem cuidados a determinadas crianças, como foi o caso de W. e de seus irmãos.

O gradativo aumento do número de crianças que participavam dos encontros, algumas limitações objetivas que a rua impõe para a realização das atividades (clima, deslocamento de materiais entre outras) e a maior sensibilização dos Agentes Comunitários de Saúde para apoiar ações voltadas às crianças fizeram a equipe redimensionar a proposta. Considerou-se que já havia acúmulo de experiência suficiente para compreender a complexidade das condições de vida de crianças e famílias da região e que se estabelecera vínculo de crianças e famílias com o serviço de saúde. Ao mesmo tempo, a equipe acreditou que trazer as crianças para o espaço do serviço de saúde seria importante para a construção de uma cultura de participação e maior apropriação dos recursos locais pelo grupo e a comunidade. Assim, a partir de agosto de 2005, constituiu-se uma tarde de brincadeiras para todas as crianças da região, na sede da UBS com participação de agentes comunitários de saúde na equipe.

\section{Brincando na Rua: desafios colocados}

Durante o período de desenvolvimento desta experiência a equipe pode perceber a importância do espaço público da rua na vida das famílias e das crianças do bairro, incluindo aquelas ainda bem pequenas, que, para a surpresa da equipe, circulavam por muito tempo, acompanhadas ou não de adultos ou de crianças maiores.

Esse cenário possibilita refletir sobre o que Ariès (1981) aponta em seu estudo sobre a criança e a família, onde, desde os tempos antigos, a rua era o lugar das intensas trocas sociais, da existência vivida em público, condição privilegiada para o aprendizado das crianças, que se viam misturadas e confundidas com os adultos. E que, embora, posteriormente, a estrutura social tenha isolado parte das crianças do espaço público, mantendo-as em instituições educacionais, nos domicílios, em espaços privados de consumo e divertimento, para a maioria das crianças moradoras de comunidades periféricas, a rua se constitui um importante espaço de lazer e de aprendizado. O espaço público influencia o desenvolvimento infantil, oferecendo um contorno social e cultural às experiências lúdicas onde as brincadeiras das crianças "são formas de cultura e processos de desenvolvimento que podem ser compreendidos como um movimento social importante para a formação de uma consciência crítica, baseada em relações interpessoais espontâneas e no fortalecimento 


\section{da comunidade" (GORBACHOV; GUZZO, 2002, p. 44)}

As mudanças nas configurações familiares e o fato de muitas mães do Jardim Boa Vista trabalharem fora de casa possibilitam que também os espaços públicos (rua e escola), a exemplo do que afirma Sarmento (2002), se tornem geradores de referência e de sociabilidade, principalmente para as gerações mais novas.

No desenvolvimento desta experiência buscou-se implementar o caráter lúdico dos encontros, a ampliação de oportunidades de prazer, de motivação e ação favorecendo possibilidade de diálogo e de participação para os presentes (KISHIMOTO, 1996; BRUNELLO, 2001).

Realizar o trabalho a partir de uma UBS trouxe contornos particulares ao projeto, dotando-o de noções de integralidade e equidade no direito à saúde (MATTOS; PINHEIRO, 2001; CAMPOS, 2003). Nesta perspectiva procurou-se transcender a idéia do cuidado às crianças focado apenas nos aspectos biológicos do desenvolvimento e do crescimento, compreensão esta que, muitas vezes, norteia grande parte das ações de saúde da UBS para esse grupo.

Tratou-se também de articular alternativas para que famílias e crianças, entre elas W. e seus irmãos, tivessem acesso à atenção à saúde e ao respeito aos direitos, de acordo com o Estatuto da Criança e do Adolescente - ECA (BRASIL, 1990). O serviço de saúde integra a rede de serviços e de proteção à criança e ao adolescente e é necessário que profissionais da saúde estejam sensibilizados para isso.

Este trabalho mostrou-se árduo e, em alguns momentos, quase impossível de ser desenvolvido, principalmente pelas dificuldades no diálogo e estabelecimento de encaminhamentos concretos para participação de crianças em serviços (escola e associação cultural local), por resistência de pais a oferecerem oportunidades existentes a seus filhos, que não apenas o cuidado dos irmãos e a escolarização. Por outro lado, as condições de vida de crianças e famílias de áreas periféricas podem tornar profissionais e serviços menos sensíveis à identificação e discussão de seus problemas, o que dificulta intervenções que articulem respostas da rede de suporte social, que, muitas vezes, se apresenta fragilizada. Porém, acredita-se que este seja um caminho possível para construção de alternativas para melhoria das condições de vida das crianças do bairro, onde o papel do serviço de saúde é essencial.

O deslocamento de profissionais de terapia ocupacional para o espaço da rua foi reconhecido, positivamente pelas crianças, familiares e serviços da comunidade. Uma forma de aprofundar o conhecimento sobre a infância e apontar a importância de espaços criativos de encontro entre crianças em áreas empobrecidas (LOPES et al., 2001).

Conhecer o contexto territorial e as condições de vida da população que se tem sob responsabilidade, tem sido premissa para pensar propostas de intervenção no campo da afirmação de direitos de crianças e jovens, constituindose questão fundamental para implementar uma prática profissional voltada para o campo social. O local de atendimento foi transferido para o espaço da rua, para os domicílios e para a comunidade. O uso da atividade foi importante mediador de relações, através das quais foi possível reconhecer capacidades, possibilidades e dificuldades das crianças, como também importante forma de expressão, por parte dos participantes, revelando desejos, potencialidades, conflitos, auxiliando na compreensão de uma determinada inserção cultural, histórica e social.

A não garantia de acesso a direitos de crianças, jovens e de suas famílias deveria convocar profissionais, comunidade e poder público a organizarem agendas públicas para discussão e promoção de ações que estabeleçam condições mais favoráveis para o desenvolvimento de crianças, jovens e suas famílias. Também, se tornou essencial a sensibilização dos trabalhadores da equipe de saúde para o tema da infância e para a necessidade de fomento de espaços de convivência para as crianças moradoras de áreas periféricas. Para a terapia ocupacional se reafirmaram possibilidades de intervenção, que colocam o campo profissional em diálogo com os processos vividos pela imensa maioria de crianças e jovens em nosso país.

Agradecimentos: aos demais participantes da experiência: Maria Cristina Tissi - Terapeuta Ocupacional - da Secretaria Municipal de Saúde de São Paulo, comissionada para atividades junto ao Curso de Terapia Ocupacional da FMUSP entre 1997 e 2004 - as estudantes de Terapia Ocupacional de $4^{\circ}$ ano Cínthia Maria dos Santos e Marília Bense Othero (de março a julho de 2004), Tatiana Pedroso e Melissa Tieko Muramoto (de agosto a dezembro de 2004), Fabiana Rocha e Mariana Satomi Romero Saito (de março a julho de 2005) e, ainda, Adriana Belmonte Moreira, Terapeuta Ocupacional substituta (de março a julho de 2005). 
AOKI, M. et al. Pelo direito de brincar. Rev. Ter. Ocup. Univ. São Paulo, v. 17, n. 2, p. 57-63, maio/ago., 2006.

AOKI, M.; OLIVER, F. C.; NICOLAU, S. M. The right to play: getting to know childhood and enhancing occupational therapy's action. Rev. Ter. Ocup. Univ. São Paulo, v. 17, n. 2, p. 57-63, maio/ago., 2006.

\begin{abstract}
An account on the development of play activity groups with children (4 to 13 years old) carried out in the street setting in a suburb of Sao Paulo city. The group was coordinated by a team of an occupational therapist and two O.T. students and is part of a project for university faculty and the local basic health unit, taking place from April 2004 until July 2005. Based on the record of meetings and discussions among professionals involved we were able to recover the trajectory of the experience. The team went to the street and for two hours carried out play activities, games and conversations. Comprehension of the dynamic of the children in this location and the promotion of meetings ruled by learning experiences and solidarity were guiding elements of these group meetings. By the contact with these children we observed inconsistencies related to the use of public space and individual demands. We noted conflicting interpersonal relationships between children which required mediation by adults and contacted the parents. Ten families were interviewed (total 17 children) to understand the family structure, the children's performance at school, their free time activities, favorite games, and family leisure activities. There was a significant adhesion and a positive acknowledgement of the intervention by the children. The team came to comprehend the complexity of the conditions in which the children, comprised in the area of this basic health unit, live. This work fomented the debate on the creation of alternative services and on civil rights.
\end{abstract}

KEY WORDS: Child. Child preschool. Child development. Child advocacy. Human rights. Occupational therapy.

\title{
REFERÊNCIAS
}

ARIÈS, P. História social da criança e da família. 2a ed. Rio de Janeiro: LTC, 1981.

BRASIL. Estatuto da criança e do adolescente. São Paulo: Cortez, 1990.

BRUNELLO, M. I. B. Ser lúdico: promovendo a qualidade de vida na infância com deficiência. 2001. Tese (Doutorado) Instituto de Psicologia, Universidade de São Paulo, São Paulo, 2001.

CAMPOS, C. E. A. O desafio da integralidade segundo as perspectivas da vigilância da saúde e da saúde da família. Ciên. Saúde Coletiva, v. 8, n. 2, p. 569-584, 2003.

GORCHACOV, A.; GUZZO, R. S. L. Brincadeiras populares, movimentos sociais e formação da consciência crítica: reflexões sobre uma experiência. Rev. Bras. Cresc. Desenv. Hum., S. Paulo, v.12 n,1, p. 43-50, 2002.

KISHIMOTO, T. M. (Org.). O jogo e a educação infantil. In: KISHIMOTO, T. K. (Org.). Jogo, brinquedo, brincadeira e a educação. São Paulo: Cortez, 1996. p. 13-43.

LOPES, R. E.; BARROS, D. D.; MALFITANO, A. P.; GALVANI, D. O espaço do brincante na experiência do projeto casarão. Rev. Ter. Ocup. Univ. São Paulo, v.12, n.1/3, p. 48-51, 2001.

MATOS, R. A.; PINHEIRO, R. Os sentidos da integralidade na atenção e no cuidado à saúde. Rio de Janeiro: UERJ-IMSABRASCO, 2001.

SARMENTO, M. J. Infância, exclusão social e educação como utopia realizável. Educ. Sociedade, v. 23, n. 78, abr. 2002.

Recebido para publicação: Mar./2006

Aceito para publicação: Abr./2006 